\title{
Crítica de arte, ayer y hoy
}

\author{
Elixabete Ansa Goicoechea \\ Instituto de Estética, Facultad de Filosofía, Pontificia Universidad Católica de Chile. \\ elansa@uc.cl
}

En cincuenta años de publicación, Aisthesis se ha constituido como una revista de referencia para la crítica de arte en el mundo hispanohablante. Esta labor se ha realizado desde diferentes disciplinas (filosofía, artes plásticas, historia, educación, antropología, etc.) y atendiendo a una gran variedad de problemáticas asociadas al arte (su inscripción en la denominación "arte", el problema de la mirada, el tema de la luz, las transformaciones mediales y técnicas que ha sufrido a lo largo de la historia, su relación con la política, la naturaleza, la cultura, etc.). Sería una tarea imposible intentar abordar en estas pocas páginas todo lo que la revista ha dicho sobre arte. Es por eso que hemos optado por recoger algunos aspectos que nos han llamado la atención en la revisión que hemos realizado, para luego resaltar aquellas problemáticas que nos parecen, a título personal, relevantes, no solo en relación con lo que se dijo sobre el arte, sino también en relación con lo que todavía queda por decir y cuestionar.

En los primeros números de Aisthesis, es inevitable no referirse a varios artículos que, enmarcados dentro de una visión católica, son referencias importantes en el estudio del arte y la estética. Me refiero a los artículos de Raimundo Kupareo u Osvaldo Lira. Además de ser Vicerrector de la Pontificia Universidad Católica de Chile, el primero fundó el Instituto de Estética y plantea en sus artículos una revisión erudita de temas cruciales sobre el arte, como por ejemplo el fin o "La muerte del arte" (1977), así como pautas indispensables a la hora de adentrarse en la interpretación artística. Osvaldo Lira fue seguidor del pensamiento católico anti-liberal español y ofrece en dos artículos, "Splendor Formae" (1967) y "Belleza y experiencia" (1977), ejemplos claros del pensamiento católico. 
En esta primera década de la revista (1966-1976), los autores citados comparten espacio con críticos de arte que podríamos denominar "impresionistas", como Antonio Romera, y con aproximaciones críticas que rescatan sobre todo la tradición europea en el arte, así como los comienzos de la pintura en Chile (para esto, véanse los artículos traducidos de Herbert Read o Thomas Munro (1967), de José Camón-Aznar (1967), Ramón Vinés Cid (1975-6), Roberto Zegers (1975-6) o Lisette Balmaceda (1975), entre otros).

Desde los primeros números también se observa que críticos como Gaspar Galaz y Milan Ivelic utilizan el espacio de la revista para proponer sus principales críticas de arte. Galaz publica su primer artículo, "La fuerza social del arte", en 1971, e Ivelic, "Percepción y pintura", en 1975-6. Destacan, entre las publicaciones de ambos, dos artículos en particular. Por un lado, una entrevista que Galaz lleva a cabo en 1971, con la colaboración de Adriana Valdés. Los autores conversan con José Balmes, Eduardo Vilches, Nemesio Antúnez, Rodolfo Opazo, Mario Carreño y Gracia Barrios. En el momento de ser entrevistado, José Balmes aún no es Decano de la Facultad de Artes de la Universidad de Chile (1972-3), pero sí Director de Artes Plásticas de la Carrera de Bellas Artes. Es el periodo previo al exilio, como el de Gracia Barrios y Nemesio Antúnez, y previo también al regreso, no a la Universidad de Chile, sino a la Católica en 1986, precisamente debido a una gestión de Ivelic y Galaz (Galende 31-2). Por el compromiso político que estos y otros artistas mostraron en aquella época hacia el proyecto de la Unidad Popular, la entrevista tiene un valor incomparable, sobre todo si tenemos en cuenta las preguntas que tocan los principales temas acerca de la relación entre arte latinoamericano y sociedad y política: 1 . "El arte y su compromiso con la realidad”; 2. “¿Un arte para 'agradar’ al público?”; 3. "El arte, hoy y aquí en Latinoamérica"; y 4. "El museo".

Por otro lado, cabe destacar también el artículo "El videoarte en Chile", de 1986, que publican en co-autoría Galaz e Ivelic. Puede considerarse un adelanto del texto más emblemático de estos críticos, Chile: arte actual (1988), pero sobre todo, nos interesa por ser un artículo temprano en el estudio de un género artístico que está surgiendo y transformándose de manera paralela a la publicación del mismo. El ensayo recoge las experiencias del videoarte en Chile, mencionando los nombres de la corriente principal, como Juan Downey, hasta las grabaciones del grupo CADA, de Carlos Altamirano o de Eugenio Dittborn, así como también las experiencias de los Encuentros de Video-Arte Franco-Chilenos que empezaron a celebrarse en 1981.

Además de estos autores, en la revista Aisthesis encontramos las críticas de arte de los profesores que le imprimieron al Instituto de Estética un sello particular, y a la crítica de arte, la necesidad de concebirla más allá del tradicional binario entre arte "culto" y arte "popular" e "indígena". Nos referimos a la labor crítica de Fidel Sepúlveda, Gastón Soublette y Jorge Montoya. Si bien el primero se dedicó principalmente al estudio de la estética oral y popular, y el segundo, al análisis de los símbolos de manera interdisciplinaria (ambos autores son comentados en otros artículos de este 
número), Jorge Montoya -ilustrador, además, de los números de fines de los setenta y comienzos de los ochenta- rastrea desde la crítica del arte, varios aspectos claves que proponen reinterpretar autores, reconsiderar la categoría "arte" o ahondar en la incidencia de autores latinoamericanos en Chile. Es el caso de sus primeros dos artículos (1975-6, 1978), donde el trabajo de Juan Francisco González es destacada como una puesta al día necesaria en la labor pictórica nacional. "La grandeza perdida del oficio" (1982) arguye en defensa de la calidad artística de la artesanía, y en dos artículos posteriores (1995 y 2000), se plantea un primer diálogo entre el muralismo mexicano y su incidencia en Chile (Siqueiros, Gregorio de la Fuente, etc.); un tipo de diálogo Sur-Sur difícil de encontrar en la crítica de arte. Tanto Ivelic y Galaz, como Sepúlveda, Soublette y Montoya no dejan de ser referentes importantes por haber mantenido un proyecto intelectual, como el del Instituto de Estética, en momentos en que el pensamiento crítico apenas sobrevivía.

Siguiendo esta tradición crítica a partir de los profesores que impartieron clases en el Instituto de Estética, uno puede observar que la crítica de arte tuvo continuidad en generaciones posteriores a la que acabamos de citar. Los profesores María Teresa Viviani (2000, 2005, 2007), Paula Honorato (2010) o Rosa María Droguett Abarca (2014), han establecido diálogos entre el arte y la filosofía contemporánea -Viviani con Heidegger (2005) y Nietzsche (2000); Honorato con Deleuze (2010)- y han propuesto una relectura del espacio museal en los circuitos contemporáneos del arte latinoamericano, como lo hace Droguett Abarca (2014).

Sin embargo, la revista no ha servido únicamente como espacio de proyección intelectual y académica para los profesores del Instituto. Desde el primer número, Aisthesis ha dedicado extensas páginas a autores y pensadores que han nutrido la crítica de arte a nivel nacional e internacional. En sus textos encontramos publicaciones de Justo Pastor Mellado, Pablo Oyarzún y Nelly Richard, todos ellos referentes importantes en la crítica de arte de los últimos treinta años.

En 1988, dos años después de haber publicado Márgenes e Instituciones (1986) y dos años antes de dirigir la Revista de Crítica Cultural (1990-2008) -ambas, publicaciones emblemáticas tanto para la crítica de arte como para la circulación del pensamiento intelectual (inter)nacional de la época-, Nelly Richard ofrece una revisión de su labor bajo el título "Las coordenadas de producción crítica que sitúan mi trabajo". En este texto, encontramos sentencias que, inscritas dentro del periodo dictatorial, pero útiles no solo para interpretar dicha época, marcan a nuestro parecer un a priori necesario para toda crítica de arte:

...[L]a necesidad o el interés de una aproximación sociocontextual al fenómeno creativo, que integre a su lectura de la obra las coordenadas de significación social, cultural, ideológica, que rigen su entorno y que esa obra reprocesa. De ahí también mi sospecha hacia la estética como "actividad desinteresada" en la tradición kantiana o neo-kantiana: esfera contemplativa gobernada por la sensibilidad, el gusto o el placer "puro"; esfera de asilamiento cortada de lo 
real y de sus conflictos de identidad (sexo, raza, clase) y enfrentamientos de poder... [Me] resulta insuficiente una estética restringida a las componentes expresivo-formales de la obra sin considerar la interactuación de los diferentes códigos de significación y de producción artística. Sobre todo en un medio como el chileno donde la violencia histórica, la desarticulación del cuerpo social y el quiebre del marco de referencias de identidad, los condicionamientos de la censura y de la autocensura, la marginalidad latinoamericana, configuran una situación-límite que sobreimprimen sus marcas de enunciación en cualquier obra o texto; marcas que la obra a veces oculta o exhibe, a veces disfraza, pero que siempre contiene a modo de claves socio-semióticas de su articulación a la coyuntura histórica (28-9).

Hemos incluido esta cita prácticamente sin ninguna omisión porque nos parece que encontramos aquí una posición crítica que acoge Aisthesis en un momento muy significativo, como es 1988, deshaciéndose de la preferencia por escrituras "impresionistas" o "academicistas", como diría la propia Richard. Textos críticos con la ideología predominante del sentido común establecido, tal y como produce Richard, constituyen un aporte fundamental para que las revistas publicadas desde un espacio académico no olviden su inscripción social y su labor comunitaria más allá del círculo universitario, y propaguen, además, voces que no encuentran en los medios culturales hegemónicos vías de difusión.

Una vez adentrados en el periodo así llamado "democrático" chileno, Pablo Oyarzún colabora en 1997 con un artículo que trata un tema recurrente en la revista y en la historia del arte a partir, y si no antes, de la década de 1960: la posibilidad del arte de "ser" en momentos de una "totalización estética de la realidad" (Oyarzún 36). Pero sobre todo, es un artículo que trata sobre la responsabilidad que debería tener la crítica de arte de identificar siempre, y a pesar de la caída del arte en la mercantilizada vida (post)moderna, el "borde” de su producción, ahí donde borde tiene que ver con la posibilidad de demoler el "restablecimiento de una mirada normativa" (38):

Cuando desaparece la obra en medio de la proliferación de las obras, le concierne a la crítica alcanzar el borde y decir su deseo, que se funda en la relación más enigmática que en la obra se borda y se trama entre deseo y presencia, de la cual permanece pendiente todo lo que llamamos historia del arte. Esa relación es el borde del que hablaba. Yo diría que todavía se da ese borde como lugar; o más bien: que todavía lo haya es la única condición bajo la cual tendría la crítica algo que decir, antes que (o antes de) guardar silencio (42).

Nos resulta indispensable subrayar esta actitud en el devenir de Aisthesis; la posibilidad de que la revista sea un espacio que tenga (y dé) que hablar en este sentido. Especialmente a partir de un momento, como es la década de los noventa, en el que Aisthesis -quizás como síntoma de la totalización estética de la que habla Oyarzún- 
empieza a publicarse en formato académico, del que dan cuenta, entre otros aspectos, los resúmenes en castellano e inglés al comienzo de cada artículo. Teniendo en cuenta que posteriormente la revista ingresa en el sistema Scielo, es indispensable no perder de vista la crítica que identifique los bordes del arte.

Justo Pastor Mellado en el número 46 de la revista, en 2009, colaboró con una revisión crítica del catálogo AIWIN: La imagen de la sombra, un proyecto que se produce en el marco de la I Trienal de Chile, una experiencia que, como es sabido, no ha tenido continuidad hasta el momento, y que bien podría analizarse desde sus "bordes". El catálogo acoge el resultado de los Talleres de Fotografía Aiwin, realizados en tres comunidades mapuches por Andrea Josch y Claudia Astete, con la edición de campo del artista venezolano Nelson Garrido. En palabras de Mellado, el catálogo propone la necesidad de dar continuidad a un proyecto que plantea la autogestión como problema central en el acercamiento del arte a las comunidades mapuches.

Aunque hayamos destacado estas tres entradas críticas, hay muchas más que se podrían mencionar, cada una resaltando un borde crítico inevitable a la hora de analizar el arte en la actualidad. Resulta estimulante, por ejemplo, observar que Aisthesis ha publicado en el 2012 y 2013 varios textos que problematizan la representación del género y de la mujer en el arte, desde diferentes perspectivas disciplinarias y cuestionando ámbitos tan diversos como la cultura mediática, la fotografía, la post-pornografía, el video, la pintura o la performance. Es el caso de los artículos de Alejandra Castillo ("Ars Disyecta", julio 2012), de Camila Mardones Bravo ("Pasiflora mística. Análisis iconológico de una pintura barroca de la Virgen de la Merced", diciembre 2012), de Valentina Montero ("Aportaciones feministas en la relación entre arte y tecnología", diciembre 2012), de Alfonso Chaparro (“"Mujeres mola’ o la máquina de imágenes míticas", julio 2013) y de Lilith Kraushaar ("Crimen y exhibición de prostitutas en el norte de Chile. Producción y uso de las imágenes del cuerpo de mujeres asesinadas", julio 2013). Como se puede observar en estos números más recientes, Aisthesis se ha relacionado de manera directa con la interdisciplinariedad y ha atraído el interés de pensadores de diferentes países: Colombia, Argentina y España, entre otros.

En este recorrido arbitrario de lo que Aisthesis ha producido en torno al pensamiento crítico sobre el arte, nos gustaría destacar un concepto que ha influido en el pensamiento de varios de los autores aquí citados y que nos ofrece un instrumento válido a la hora de pensar el espacio de la revista y su reflexión artística. Pablo Oyarzún, en Anestética del readymade (2000), definía los ready-made de Marcel Duchamp a partir del concepto de "síntesis disyuntiva" de Gilles Deleuze. Estos objetos-arte ponen en suspensión, según Oyarzún, el carácter de objeto industrial, por un lado, elegido por el artista a la hora de pensar la instalación en el museo, y el carácter de "obra artística”, por otro, tal y como esta se entendía según el concepto de estética kantiana, asociado a la autonomía de la obra arte en la sociedad burguesa. La síntesis disyuntiva que procura el ready-made, además de suspender el carácter de objeto y obra, instala la posibilidad de diversas lecturas en la conjunción disyunta del objeto en obra. 
Veinte años antes, aunque refiriéndose a una producción artística posterior, como es el trabajo de Carlos Leppe en los setenta, Nelly Richard narra en Cuerpo correccional (1980) que "la pose como descalce sexual te estatuye descoincidente, dicotómico / te estatuye difractado" (31, énfasis añadido). El establecer u ordenar en la dispersión, al que alude esta última frase - "estatuye difractado"-, nos parece que remite a una idea similar. Se refiere aquí a la suspensión de lo natural o, más precisamente, lo naturalizado como el retrato masculino o femenino. Las poses que componen el registro fotográfico de Cuerpo correccional (piensen en "Gertrude Stein, cita-objeto", de 1977), mitad hombre, mitad mujer, con una mirada siniestramente sobria, hablan de la suspensión de lo natural en el cuerpo, y la suspensión del retrato como captura de registro biopolítico de los cuerpos. Además, remiten de alguna manera a aquella fascinación primera de Baudelaire hacia el maquillaje de "Las mujeres y las mujerzuelas" que sentían "la necesidad de superar la naturaleza" (126).

En Ars Disyecta (2014), libro que procede de un estudio ampliado del artículo con el que la filósofa feminista Alejandra Castillo contribuye a Aisthesis, vuelve a aparecer el concepto deleuziano, en esta ocasión para pensar y problematizar el trabajo de Felipe Rivas San Martín en Ideología (2012), obra que fue censurada en el año en curso (2016), pero que finalmente se presentó en el Centro de Extensión del Consejo Nacional de la Cultura y las Artes de Valparaíso. Para Castillo, la disyunción deleuziana tiene que ver en el caso de Rivas San Martín con la posibilidad de pensar el deseo como potencia disruptiva de los lugares comunes de la ideología tradicional de izquierda (64-72).

Quizás una de las posiciones más críticas y abarcadoras de esta noción deleuziana la ofrezca Willy Thayer en su análisis del arte contemporáneo. A propósito de la exposición Cambio de Aceite, que se celebró en el Museo de Arte Contemporáneo de Santiago de Chile en 2003, Thayer afirma que lejos de pensar la potencia artística dentro de un marco discursivo de (neo)vanguardia, donde se revelan "retorno[s] dramático[s] de lo reprimido" o "retorno[s] farsesco[s] de lo obsoleto", cabe pensar:

Todo ello a la vez, si se quiere, como activación de la temporalidad en la coincidencia de sus metonimias. Estas últimas no responden, entonces, a la lógica de la cripta como guarda de un cadáver (profundidad), sino a la del cenotafio como superficie vacía. Cenotafios dispuestos en un juego de aceleraciones que al chocar o rozarse producen memorias; no como recuerdos nuevos, sino como pasajes, disyunciones, quiebres de memoria, pensamientos más veloces que la síntesis, que exceden un orden resuelto de representación (58, énfasis nuestro).

Esta noción del collage como síntesis disyuntiva que cortocircuita y desborda toda posibilidad de (re)presentación nos ofrece una posición de alerta primordial para pensar una crítica de arte que no se convierta en valor de cambio.

Se propone, entonces, dejar de lado cualquier concepto que apele a una síntesis productiva y normalizadora, para pensar más bien la apertura, es decir, la relación con 
lo abierto que la disyunción propone en todos los ámbitos. Esto es lo que nos gustaría proponer con la crítica de arte en Aisthesis. Más que buscar que esta trate "X" temas o "Y" perspectivas, que ponga en suspensión tanto las obras inscritas en los circuitos artísticos, como la propia crítica. Es decir, que en la labor de escritura que la revista acoja, se suspenda también y sobre todo, la escritura académica y academizante, y la escritura que tienda a normalizar discursos y obras que bordeen el sentido común, que bordeen la estetización de la vida cotidiana.

\section{Referencias}

Baudelaire, Charles. El pintor de la vida moderna. Trad. Alcira Saavedra. Valencia: Colegio oficial de aparejadores y arquitectos técnicos de la región de Murcia, Consejería de educación y cultura de la región de Murcia y Fundación Cajamurcia, 2004. Impreso.

Castillo, Alejandra. Ars Disyecta. Santiago: Palinodia, 2014. Impreso.

Galende, Federico. Filtraciones I. Conversaciones sobre arte en Chile (de los 60's a los 80's). Santiago: Editorial ARCIs y Cuarto Propio, 2007. Impreso.

Oyarzún, Pablo. Anestética del ready-made. Santiago: Lom Ediciones y Universidad ARCIs, 2000. Impreso.

Richard, Nelly. Cuerpo correccional. Santiago: V.I.S.U.A.L., 1980. Impreso.

Thayer, Willy. "Del Aceite al collage". Cambio de Aceite. Santiago: Ocho Libros, 2003. 42-59. Impreso. 